\title{
Production and Characterization of Biodiesel from Avocado Peel Oils using Experimental Analysis (ANOVA)
}

\author{
Tafere Aga Bullo ${ }^{1 *}$ and Feyissa Bekele Fana ${ }^{2}$
}

\begin{abstract}
${ }^{1}$ Department of Chemical Engineering, Faculty of Engineering, Jimma University, Jimma Institute of Technology, Ethiopia
${ }^{2}$ Department of Chemical Engineering, Faculty of Engineering, Wollo University, Wollo Institute of Technology, Ethiopia
\end{abstract}

Received: May 04, 2021, Revised: June 22, 2021, Accepted: June 23, 2021, Available Online: June 28, 2021

\begin{abstract}
The crisis of energy due to the increasing awareness of the depletion of fossil fuel resources, biodiesel is an alternative energy source and promising potential energy that grows rapidly, due to its high contribution to the environment friendly, renewable, nontoxicity, biodegradability, essentially sulfur-free, and as a strategical source of renewable energy in substitution to diesel oil and contributes a minimal amount of net greenhouse gases. In this study, the extracted oil used for biodiesel production from waste avocado peel was investigated in a laboratory approach. Experimental results evaluate the major optimum process parameters for base-catalyzed transesterification on biodiesel yield as well as its properties. The most important variables affecting methyl ester yield during the transesterification reaction are the molar ratio of alcohol to oil and the reaction temperature. A 95.2\% FAME conversion was obtained using a methanol/oil ratio of $6: 1,1.21 \mathrm{~g} \mathrm{NaOH}$, reaction time $67.5 \mathrm{~min}$, and $60{ }^{\circ} \mathrm{C}$ reaction temperature. Important properties of (characterization) produced biodiesel are, (pHof 7.8, specific gravity of 0.88 , density at $15{ }^{\circ} \mathrm{C}, \mathrm{kg} / \mathrm{m}^{3}$, the kinematic viscosity of biodiesel was found to be $4.22 \mathrm{~m}^{2} \cdot \mathrm{s}^{-1}$ at $40{ }^{\circ} \mathrm{C}$, the flashpoint was $161{ }^{\circ} \mathrm{C}$ and Cetane number of 49 are well-matched the relevant international standards for biodiesel quality produced. This result shows that the oil obtained from avocado peel can be used for biodiesel production as an alternative fuel as compared to those of ASTM and EN standards.
\end{abstract}

Keywords: Avocado Peel Oils, Biodiesel, Soxhlet Extraction, Transesterification.

This work is licensed under a Creative Commons Attribution-Non Commercial 4.0 International License.

\section{Introduction}

Energy is one of the most important resources for humankind and its sustainable development. Today, the energy crisis becomes one of the global issues challenging. Fuels are of great importance because they can be burned to yield significant amounts of energy [1]. Biodiesel is the most promising renewable alternative fuel and the challenge of energy problem and sustainability in our today's world increases the number of population and sustainability have been problems due to the industrial revolution. Since it has considerable attention due to its renewability, reliable, secure, biodegradability, clean, environmental eco-friendly, nontoxicity, energy-efficient, less emission of gaseous and sustainable energy resources substitution of fulfilling energy security needs without sacrificing engine's operational performance thus it provides a feasible solution to the twin crises of fossil fuel depletion and environmental degradation [2]. It meets the currently increasing huge demands of world energy which is dependent on petroleum-based fuel resources. However, energy is often known as the primary success of a country's development. It is often used as an indicator to measure the level of economic growth in a country. The occurrence of oil depletion, global warming, and the greenhouse effect has become an alarming condition where it is needed to search for an alternative energy source [3].

Now a day the world has been stimulated with technological development to use vegetable-oil-derived fuel in a diesel engine. Biodiesel is nothing but, chemically treated triglycerides that is an alternative to petrodiesel. However, using vegetable oil to replace fuel caused the food versus fuel issue all over the world. So the idea of using waste vegetable oil (WVO) has been introduced as an economical solution, which also gives a waste management solution [4].

The chemical process used to produce biodiesel is called transesterification. However, due to the high free fatty acid content of the cheaper non-edible feedstock conventional alkalicatalysed transesterification is not possible for biodiesel production. An acid pre-treatment is essential for converting the free fatty acid to corresponding methyl/ethyl ester followed by which usual transesterification is employed [5].

Base catalysed transesterification is the most commonly used technique as it is the most economical process basecatalysed involves stripping the glycerine from the fatty acids with a catalyst such as sodium or potassium hydroxide, and replacing it with anhydrous alcohol, usually methanol [6]. Biodiesel is a good alternative fuel for internal combustion engines is defined as a mixture of monoalkyl esters of long-chain fatty acids (FAME) derived from a renewable feedstock, such as vegetable oil or animal fat, are the most promising energy sources for our country [7].

Biodiesel is a renewable energy resource and biodegradable fuel to guarantee the sustainability of energy and produced from a wide range of naturally occurring fats and extract oils by a transesterification reaction process in which the triglycerides are broken down and fatty acid methyl esters (FAMEs) are formed. The fatty acid dissemination of the original oil is reserved in the biodiesel; hence the physical and chemical properties of the biodiesel have some dependence on the feedstock used. Biodiesel is substitute energy for diesel engines that is produced by chemically reacting a vegetable oil or animal fat with an alcohol such as methanol through a transesterification reaction method. 
Biodiesel is a carbon-free fuel because there is no overall increase in $\mathrm{CO}_{2}$ in the atmosphere due to recycling by the growing plants used to feed the biodiesel industry. Emissions of $\mathrm{CO}_{2}, \mathrm{CO}_{3}, \mathrm{CO}$, unburnt hydrocarbons, and particulate matter are lower than that of petroleum diesel [8].

Currently, the increasing rate of biodiesel is the key difficulty to commercialization. The increasing cost of biodiesel is mainly due to the cost of the feedstock used. One way of reducing the biodiesel costs is to use the less costly feedstock containing fatty acids such as inedible oils, waste cooking oil, and by-products of the refining vegetable oils [9]. However, using the waste avocado peels is one from this and its use as alternative raw materials.

\subsection{Production of biodiesel and raw materials}

Biodiesel is a substitute liquid fuel that can significantly replace conventional diesel and reduce exhaust pollution and engine maintenance costs. There are different types of feedstocks that are used for the production of biodiesel. These include palm seed oil, waste cooking vegetable oil, sunflower seed oil, cottonseed oil, jatropha seed oil, castor beans oil, and animal fats [10], [11]. The extracted oil from avocado peel is used for the manufacture of biodiesel through the process called transesterification reaction that is a process by which methanol alcohol reacts with the extracted oil in the presence of catalysts sodium hydroxide.

Avocado peel is a waste where so many people are throwing away after using the fruit flesh. Avocado fruit is one of the most popular fruit in Ethiopia as a result there is a significant rise in avocado fruit consumption and consequently an increase in avocado peel waste generation. currently, there is a large yield gap of avocado productivity in Ethiopia (about $4.2 \mathrm{t} \mathrm{ha}^{-1}$ ) as compared to the world $\left(7 \mathrm{tha}^{-1}\right)$ of which lack of improved avocado varieties has been a bottleneck [12]. The seed and peel weigh about $16 \%$ and $11 \%$, respectively. However, these proportions vary among cultivars [13]. Therefore, alternative routes are needed for this waste management. This waste cannot be used still for any consumption. The presence of nitrogen allows it to be directly used as fertilizer or as soil improver (or compost) [8]. Avocado peels are used to evaluate the possibility of using and transforming waste into something valuable product, namely biodiesel thereby contributing towards alternative energy supply as well as recycles what would be discarded and resolves energy scarcity.

\section{Materials and Method}

\subsection{Materials used for the production of biodiesel}

Materials that were used during the experiment work are as follows: avocado peel oil, filter paper, heater mantle, knife, pipette, measuring cylinder, hydrometer, conical flask, plastic bags, hot plate, condenser, $\mathrm{pH}$ meter, measuring cylinder, and Piece of cloth.

\subsection{Equipment}

The equipment used during this experimental work are; Soxhlet extractor, vacuum pump, chiller, water bath, the oven was used for drying avocado peel and used to evaporate the excess alcohol from the extracted oil, Vibro viscometer, conical flasks, three-neck flasks, sample bottles, weighing balance, magnetic stirrer, test tubes, milling machine, FT-IR, sieve, beaker, density bottle, measuring cylinder, extraction glass column, heating device, refractometer, thermometer, and separation.

\subsection{Chemicals (Reagent)}

Methanol was the most commonly used alcohol. N-hexane (99\%) was used as a solvent for oil extraction from avocado peel powdered. The most commonly used catalyst was alcoholic sodium hydroxide $(\mathrm{NaOH})(97 \%)$, hydrochloric acid $(\mathrm{HCl})$, distilled water, and phenolphthalein indicator.

\section{Biodiesel Production Process}

There are many different production methods that can be used to produce biodiesel. From this transesterification process is the most popular method. Transesterification is the most conventional (popular way) and promising method used for biodiesel production. This is because this method is relatively easy, small reaction times, a straight conversion process, easy to operation, it significantly reduces the viscosity of vegetable oils without affecting the heating value of the original fuel, environmentally friendly, more conversion efficiency and quality of the converted fuel [2].

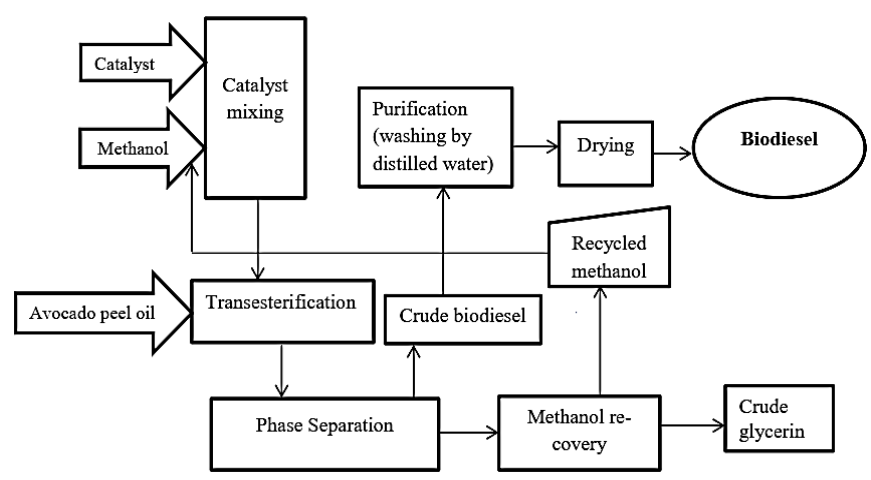

Fig. 1

Fig. 1 The production process of the biodiesel by transesterification reaction.

\subsection{The Transesterification procedure}

The transesterification process is the most common method to produce biodiesel, which is used for a catalyzed chemical reaction (Fig. 1). The production process requires a catalyst, usually a strong base, such as sodium hydroxide and potassium hydroxide [14], [15]. The biodiesel production process by transesterification reaction is made using three main components are; oil extracted from avocado peel and methanol alcohol, and a base catalyst sodium hydroxide is used in the experiments. A $500 \mathrm{ml}$ three-neck flask equipped with a magnetic stirrer, thermometer, and condenser are used during experimental work. The oil was stirred and heated in a water bath with the electric thermometer, within a temperature deviation of $1^{\circ} \mathrm{C}$. The procedures for the biodiesel production by transesterification reaction are:

1. Mixing of the methanol and the catalyst sodium hydroxide in a $200 \mathrm{ml}$ beaker using the ratio of methanol and catalyst concentration respectively. A measured quantity of methanol was poured into a beaker and the sodium hydroxide pellet was measured in the weighing balance to get exactly the weight, and mix with methanol to $50{ }^{\circ} \mathrm{C}$ (in a water bath) and stirred manually until the catalyst is completely dissolved in methanol. During this reaction, the moisture level should be kept as low as possible. The 
formation of soap decreases the biodiesel yield, consumes the catalyst and complicates the separation and purification process.

2. Methanol and sodium hydroxide solution was poured in the warm avocado peel oil in a $500 \mathrm{ml}$ three-neck flask and stirred for (45-90) minutes using a magnetic stirrer at 500 rpm. After the reaction was completed, it was allowed to settle for 24 hours in a separating funnel.

\subsection{Separation process}

After the reaction was completed, the separation process is one of the most essential measures of biodiesel production. The production of biodiesel from the extracted oil by transesterification process is normally composed of biodiesel, glycerin, and other impurities. The properties of the fuel are strongly influenced by the impurity of the biodiesel product. Normally, the biodiesel is separated from byproduct glycerin using a simple gravitational settling (density difference) method (Fig. 2) and left for 24 hours. The separation process using the separation funnel was considered cost-effective. After 24 hours, two different layers were seen in the separating funnel. The above biodiesel layer was separated for further purified and the lower glycerol layer was decanted off.

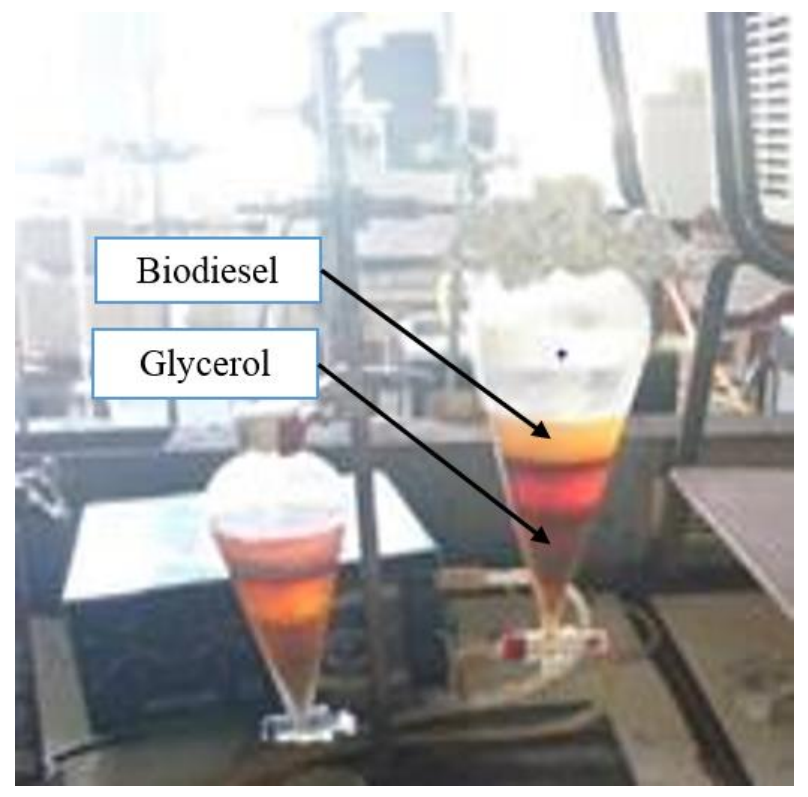

Fig. 2 Separation processes.

3.3 Washing and Drying

\subsubsection{Washing of crude biodiesel}

Once, separation has been done, the purification of the ester phase is necessary to ensure that the biodiesel meets the standard specifications of ASTM and EN. After the phase separation of glycerol and biodiesel, still has an excessive amount of soaps, catalyst, FFAs, water, methanol, glycerides, and other impurities. If these impurities are not reduced to their bounds value, this will have effects on the biodiesel as given in Table 1 and it may not meet the ASTM. The biodiesel is washed with warm distilled water to remove any impurities left in biodiesel after the reaction, and the initial settling is complete. The impurities include (primarily) excess alcohol, excess catalyst, soap formation glycerine, and a small amount of leftover lye. The ratio of water to biodiesel, $50 \%$ (related to the volume) (v/v) used is warmed to $50{ }^{\circ} \mathrm{C}$ for the washing of the biodiesel to extract impurities passed through the esters and other impurities.
The washing process of produced biodiesel was repeated until the $\mathrm{pH}$ of the biodiesel becomes relatively neutral. When biodiesel is first made, it is quiet with a pH of between 8 and 9 . Washing with distilled water is sufficient to improve impurities bringing the $\mathrm{pH}$ down biodiesel becomes relatively neutral.

Table 1 Effects of Impurities on biodiesel performance [15].

\begin{tabular}{ll}
\hline $\begin{array}{l}\text { Impurity of } \\
\text { produced } \\
\text { BD }\end{array}$ & Effects of impurities on biodiesel \\
\hline FFAs & $\begin{array}{l}\text { Corrosion and low oxidation stability. } \\
\text { Water }\end{array}$ \\
& $\begin{array}{l}\text { Hydrolysis (free fatty acid and alcohol } \\
\text { formation), corrosion, bacteriological } \\
\text { growth (filter blockage). }\end{array}$ \\
Methanol & $\begin{array}{l}\text { Low values of density, viscosity, and low } \\
\text { flashpoint. }\end{array}$ \\
soap, catalyst & $\begin{array}{l}\text { Deposit in the injectors, filter blockage } \\
\text { (sulfate ashes), and engine weakening. }\end{array}$ \\
Glycerol & Settling problems. \\
\hline
\end{tabular}

Table 2 Physico-chemical Properties of the obtained biodiesel and avocado peel oil and the standards of biodiesel in the United States (ASTM D-67510 and Europe (EN 14214).

\begin{tabular}{|c|c|c|c|c|}
\hline Property & $\begin{array}{c}\text { Avocado } \\
\text { peel oil }\end{array}$ & $\begin{array}{c}\text { Biodiesel } \\
\text { Yields }\end{array}$ & $\begin{array}{c}\text { EN } \\
14214\end{array}$ & $\begin{array}{l}\text { ASTM } \\
\text { D-6751 }\end{array}$ \\
\hline $\mathrm{PH}$ & 6.2 & 7.8 & $5-6.7$ & $7-9$ \\
\hline $\begin{array}{l}\text { Density at } 15 \\
{ }^{0} \mathrm{C}, \mathrm{kg} / \mathrm{m}^{3}\end{array}$ & 910 & 880 & $\begin{array}{c}860- \\
90\end{array}$ & \\
\hline Specific gravity & 0.91 & 0.88 & $\begin{array}{c}0.86- \\
0.9\end{array}$ & \\
\hline $\begin{array}{c}\text { Kinematic } \\
\text { viscosity at } 40 \\
{ }^{0} \mathrm{C}, \mathrm{cSt}\end{array}$ & 5.1 & 4.22 & $\begin{array}{l}3.5- \\
5.0\end{array}$ & $1.9-6.0$ \\
\hline Flashpoint, $\left({ }^{0} \mathrm{C}\right)$ & & 161 & $>120$ & $>130$ \\
\hline API & & 31.14 & & $30-45$ \\
\hline $\begin{array}{c}\text { Esters content } \\
\%\end{array}$ & 38 & 95.2 & & \\
\hline HHV (MJ/kg) & 40 & 41.25 & $\begin{array}{c}36- \\
40\end{array}$ & $40-42$ \\
\hline Fire point $(0 \mathrm{C})$ & 250 & 190 & & -- \\
\hline $\begin{array}{l}\text { Iodine value }, \mathrm{g} \\
\mathrm{I}_{2} / 100 \mathrm{~g}\end{array}$ & 82 & 114.21 & $<120$ & \\
\hline Cetane number & & 49 & $>51$ & $>47$ \\
\hline $\begin{array}{l}\text { Acid value, } \mathrm{g} \\
\mathrm{NaOH} / \mathrm{g}\end{array}$ & 8 & 0.4 & & $<0.5$ \\
\hline Free fatty acids & 4.4 & 0.2 & & $<0.24$ \\
\hline $\begin{array}{c}\text { Refractive index } \\
@ 40{ }^{\circ} \mathrm{c}\end{array}$ & & 1.54 & & $1.4-1.7$ \\
\hline $\begin{array}{c}\text { Saponification } \\
\text { value }(\mathrm{gKOH} / \mathrm{g})\end{array}$ & 200 & & & \\
\hline
\end{tabular}




\subsubsection{Drying (Evaporation) process}

The last step was the drying process. Drying biodiesel requires a little more than heating the final biodiesel at $65^{\circ} \mathrm{C}$, for 15 - 20 minutes until any remaining moisture (water) evaporates and is removed from the sample. After the biodiesel is washed and dried, the yield of biodiesel production must be analyzed to confirm the standard specifications, and the product was then characterized using an empirical formula to confirm the biodiesel production yield and consider biodiesel yield with its standard.

\section{Results and Discussions}

\subsection{Physicochemical Properties of Biodiesel}

The production of biodiesels from avocado peel oil was characterized by empirical formula and FT-IR analysis. The extracted oil and the biodiesels of physicochemical properties are given in Table 2 comparing with the limit value below in Table 2 [17].

\subsection{Statistical Analysis of the Experimental Results}

Statistical software analysis of the model was performed to evaluate the analysis of variance (ANOVA). The regression analysis and analysis of variance will be used as one of the primary tools for statistical data analysis, to generate surface plots, using the fitted equation, and by holding one of the independent constant variables using the Design Expert 6.8 program. The design summary is given in Table 3.

The predicted percentage conversion of the oil to biodiesel values using the conducted experimental design expert is 26 runs are shown in Table 3

- The percentage actual yield of biodiesel produced at different process parameters was calculated using the formula as: Yield of FAME (biodiesel \%) $=\frac{\text { weight of BD produced }}{\text { weight of oil used }} \times 1$ 100

Table 3 Design Summary of factorial designs.

\begin{tabular}{|l|l|}
\hline \multicolumn{2}{|l|}{ Design Summary of Design expert ${ }^{\circledR} 6.8$ software } \\
\hline Study type & Response surface \\
\hline Initial design & CCD \\
\hline Design model & Quadratic, polynomial \\
\hline Run & 26 \\
\hline
\end{tabular}

Table 4 Actual versus Predicted model of biodiesel yield.

\begin{tabular}{|c|c|c|c|c|c|c|c|c|}
\hline $\begin{array}{c}\text { Standard } \\
\text { Order }\end{array}$ & Residual & Leverage & $\begin{array}{l}\text { Student } \\
\text { Residual }\end{array}$ & $\begin{array}{c}\text { Cook's } \\
\text { Distance }\end{array}$ & Outlier T & $\begin{array}{c}\text { Run } \\
\text { Order }\end{array}$ & $\begin{array}{c}\text { Actual } \\
\text { Value }\end{array}$ & $\begin{array}{c}\text { Predicted } \\
\text { Value }\end{array}$ \\
\hline 1 & -0.22 & 0.687 & -0.244 & 0.009 & -0.233 & 3 & 67.60 & 67.82 \\
\hline 2 & 1.36 & 0.687 & 1.484 & 0.323 & 1.582 & 10 & 72.90 & 71.54 \\
\hline 3 & -0.70 & 0.687 & -0.767 & 0.086 & -0.752 & 18 & 69.50 & 70.20 \\
\hline 4 & -0.37 & 0.687 & -0.407 & 0.024 & -0.391 & 7 & 73.70 & 74.07 \\
\hline 5 & -0.71 & 0.687 & -0.774 & 0.088 & -0.758 & 21 & 69.50 & 70.21 \\
\hline 6 & -0.32 & 0.687 & -0.354 & 0.018 & -0.340 & 20 & 73.30 & 73.62 \\
\hline 7 & 1.71 & 0.687 & 1.864 & 0.509 & 2.149 & 4 & 78.40 & 76.69 \\
\hline 8 & -0.66 & 0.687 & -0.719 & 0.076 & -0.702 & 25 & 79.60 & 80.26 \\
\hline 9 & -0.29 & 0.687 & -0.319 & 0.015 & -0.306 & 22 & 68.70 & 68.99 \\
\hline 10 & -0.76 & 0.687 & -0.826 & 0.100 & -0.814 & 2 & 70.90 & 71.66 \\
\hline 11 & 1.28 & 0.687 & 1.392 & 0.284 & 1.462 & 9 & 72.90 & 71.62 \\
\hline 12 & -0.24 & 0.687 & -0.265 & 0.010 & -0.253 & 16 & 74.20 & 74.44 \\
\hline 13 & 1.32 & 0.687 & 1.440 & 0.304 & 1.525 & 12 & 68.50 & 67.18 \\
\hline 14 & -0.24 & 0.687 & -0.266 & 0.010 & -0.254 & 26 & 69.30 & 69.54 \\
\hline 15 & -2.31 & 0.687 & -2.517 & 0.928 & $-3.687^{*}$ & 13 & 71.60 & 73.91 \\
\hline 16 & 1.17 & 0.687 & 1.277 & 0.239 & 1.319 & 1 & 77.60 & 76.43 \\
\hline 17 & -0.88 & 0.901 & -1.696 & 1.740 & -1.882 & 23 & 87.10 & 87.98 \\
\hline 18 & 0.26 & 0.976 & 1.040 & 2.981 & 1.044 & 6 & 95.20 & 94.94 \\
\hline 19 & -2.24 & 0.145 & -1.475 & 0.025 & -1.571 & 11 & 90.70 & 92.94 \\
\hline 20 & -0.50 & 0.144 & -0.330 & 0.001 & -0.317 & 8 & 92.90 & 93.40 \\
\hline 21 & -0.36 & 0.400 & -0.279 & 0.003 & -0.267 & 17 & 92.70 & 93.06 \\
\hline 22 & 0.53 & 0.400 & 0.414 & 0.008 & 0.398 & 15 & 93.80 & 93.27 \\
\hline 23 & -0.68 & 0.400 & -0.536 & 0.013 & -0.518 & 5 & 91.50 & 92.18 \\
\hline 24 & 0.85 & 0.400 & 0.671 & 0.020 & 0.653 & 14 & 92.90 & 92.05 \\
\hline 25 & 1.51 & 0.119 & 0.979 & 0.009 & 0.977 & 19 & 93.20 & 91.69 \\
\hline 26 & 1.51 & 0.119 & 0.979 & 0.009 & 0.977 & 24 & 93.20 & 91.69 \\
\hline
\end{tabular}

* exceeds limits 
Table 5 Analysis of variance (ANOVA) for the quadratic model of esterification.

\begin{tabular}{|c|c|c|c|c|c|c|}
\hline Source & $\begin{array}{c}\text { Sum of } \\
\text { Squares }\end{array}$ & DF & $\begin{array}{c}\text { Mean } \\
\text { Square }\end{array}$ & $\begin{array}{c}\text { F } \\
\text { Value }\end{array}$ & Prob $>$ F & \\
\hline Model & 2661.13 & 14 & 190.08 & 70.65 & $<0.0001$ & Significant \\
\hline A & 38.88 & 1 & 38.88 & 14.45 & 0.0029 & \\
\hline B & 85.97 & 1 & 85.97 & 31.95 & 0.0001 & \\
\hline $\mathrm{C}$ & 19.14 & 1 & 19.14 & 7.11 & 0.0219 & \\
\hline $\mathrm{D}$ & 7.09 & 1 & 7.09 & 2.64 & 0.1327 & \\
\hline $\mathrm{A}^{2}$ & 19.78 & 1 & 19.78 & 7.35 & 0.0202 & \\
\hline $\mathrm{B}^{2}$ & 22.65 & 1 & 22.65 & 8.42 & 0.0144 & \\
\hline $\mathrm{C}^{2}$ & 6.84 & 1 & 6.84 & 2.54 & 0.1391 & \\
\hline $\mathrm{D}^{2}$ & 0.56 & 1 & 0.56 & 0.21 & 0.6570 & \\
\hline $\mathrm{AB}$ & 0.024 & 1 & 0.024 & 8.857E-003 & 0.9267 & \\
\hline $\mathrm{AC}$ & 0.090 & 1 & 0.090 & 0.033 & 0.8582 & \\
\hline $\mathrm{AD}$ & 1.10 & 1 & 1.10 & 0.41 & 0.5352 & \\
\hline $\mathrm{BC}$ & 16.81 & 1 & 16.81 & 6.25 & 0.0295 & \\
\hline $\mathrm{BD}$ & 0.063 & 1 & 0.063 & 0.023 & 0.8816 & \\
\hline $\mathrm{CD}$ & 17.64 & 1 & 17.64 & 6.56 & 0.0265 & \\
\hline Residual & 29.59 & 11 & 2.69 & & & \\
\hline Lack of Fit & 29.59 & 10 & 2.96 & & & \\
\hline Pure Error & 0.000 & 1 & 0.000 & & & \\
\hline Cor Total & 2690.72 & 25 & & & & \\
\hline
\end{tabular}

The model equation that relates the transesterification reaction process variables in terms of actual value after eliminating the insignificant terms was given below. The predicted model for the percentage of biodiesel equation in terms of Coded factors is shown in the equation below:

Biodiesel yield $=+91.69+1.56 * \mathrm{~A}+2.32 * \mathrm{~B}+1.09 *$ $\mathrm{C}-0.67 * \mathrm{D}-356.10 * \mathrm{~A} 2+147.62 * \mathrm{~B} 2+147.09 * \mathrm{C} 2$ $+42.09 * \mathrm{D} 2+0.039 * \mathrm{~A} * \mathrm{~B}-0.075 * \mathrm{~A} * \mathrm{C}-0.26 *$ $\mathrm{A} * \mathrm{D}+1.03 * \mathrm{~B} * \mathrm{C}+0.063 * \mathrm{~B} * \mathrm{D}-1.05 * \mathrm{C} * \mathrm{D}$

$$
\begin{array}{ll}
\text { where } & \text { A - a molar ratio of oil to methanol } \\
\text { B }- \text { Reaction temperature } \\
\text { C - Reaction time } \\
\text { D - Amount of catalyst }
\end{array}
$$

Equation (2) provided the coefficients of the model by using a quadratic model equation. From the ANOVA the response surface quadratic model by the transesterification reaction, the Model F-value of 70.65 implies the model is significant. There is only a $0.01 \%$ chance that a "Model F-value" this large could occur due to noise. Values of "Prob $>F^{2}$ less than 0.0500 indicate model terms are significant. In this case, $\mathrm{A}, \mathrm{B}, \mathrm{C}, \mathrm{A}^{2}, \mathrm{~B}^{2}$, in addition, the interaction $\mathrm{BC}$ and $\mathrm{CD}$ are significant models. From this Prob > F Values greater than 0.1000 indicate the model terms are not significant. ANOVA for the quadratic model for esterification is evaluated in Table 5.

From the Table 5, F-values of the model coefficients, the reaction temperature in both linear and quadratic is less than 0.0001. This indicated that reaction temperature is the most significant in determining the model than the other and the value of the methanol to oil molar ratio is the second. However, to minimize error, all of the coefficients were measured in the design. The Lack of Fit F-value of 2.96 indicates its insignificance relative to the pure error. Non-significant lack of fit is good since we want the model to fit.

Table 6 Model adequacy measures from the model.

\begin{tabular}{|c|c|c|c|}
\hline Std. Dev. & 1.64 & R-Squared & 0.9890 \\
\hline Mean & 80.05 & Adj R-Squared & 0.9750 \\
\hline C.V. \% & 2.05 & Pred R-Squared & 0.8528 \\
\hline Press & 396.15 & Adeq Precision & 22.281 \\
\hline
\end{tabular}

Table 6 shows the model adequacy measures from the model. The "Pred R-Squared" of 0.8528 is in reasonable agreement with the "Adj R-Squared" of 0.9750 in less than 0.15 difference as one might expect. "Adeq Precision" measures the signal-to-noise ratio due to random error. A ratio of 22.281 indicates an adequate signal. Therefore, this model can be used to navigate the design space.

The regression coefficients and the corresponding 95\% CI (Confidence Interval) Low and High were presented in Table 7. If zero was in the range high and low 95\% Confidence interval, the factors do not affect. From the 95\% CI High and Low values of each model term, it could be concluded that the regression coefficients of catalyst concentration and the interaction terms of the molar ratio of oil to methanol and reaction time have a highly significant effect on biodiesel production. 
T.F. Bullo and F.B. Fana /JEA Vol. 02(02) 2021, pp 104-111

Table 7 Regression coefficients and significance of response surface quadratic model for transesterification.

\begin{tabular}{|c|c|c|c|c|c|c|}
\hline \multirow[t]{2}{*}{ Factor } & \multirow{2}{*}{$\begin{array}{l}\text { Coefficient } \\
\text { Estimate }\end{array}$} & \multirow{2}{*}{$\mathrm{DF}$} & \multirow{2}{*}{$\begin{array}{c}\text { Standard } \\
\text { Error }\end{array}$} & \multicolumn{2}{|c|}{$95 \% \mathrm{CI}$} & \multirow{2}{*}{ VIF } \\
\hline & & & & Low & High & \\
\hline Intercept & 91.69 & 1 & 0.57 & 90.45 & 92.94 & \\
\hline A & 1.56 & 1 & 0.41 & 0.66 & 2.46 & 1.00 \\
\hline B & 2.32 & 1 & 0.41 & 1.41 & 3.22 & 1.01 \\
\hline $\mathrm{C}$ & 1.09 & 1 & 0.41 & 0.19 & 1.99 & 1.00 \\
\hline $\mathrm{D}$ & -0.67 & 1 & 0.41 & -1.57 & 0.24 & 1.00 \\
\hline $\mathrm{AB}$ & 0.039 & 1 & 0.41 & -0.86 & 0.94 & 1.00 \\
\hline $\mathrm{AC}$ & -0.075 & 1 & 0.41 & -0.98 & 0.83 & 1.00 \\
\hline $\mathrm{AD}$ & -0.26 & 1 & 0.41 & -1.17 & 0.64 & 1.00 \\
\hline $\mathrm{BC}$ & 1.03 & 1 & 0.41 & 0.12 & 1.93 & 1.00 \\
\hline $\mathrm{BD}$ & 0.063 & 1 & 0.41 & -0.84 & 0.97 & 1.00 \\
\hline $\mathrm{CD}$ & -1.05 & 1 & 0.41 & -1.95 & -0.15 & 1.00 \\
\hline
\end{tabular}

Table 8 Statistics model summary of the response quadratic model for transesterification reaction.

\begin{tabular}{|c|c|c|c|c|c|c|c|c|c|c|}
\hline Source & $\begin{array}{l}\text { Sum of } \\
\text { Squares }\end{array}$ & DF & $\begin{array}{l}\text { Mean } \\
\text { Square }\end{array}$ & $\begin{array}{c}\text { F - } \\
\text { Value }\end{array}$ & $\begin{array}{l}\text { P-value } \\
\text { Prob }>\text { F }\end{array}$ & $\begin{array}{l}\text { Std. } \\
\text { Dev. }\end{array}$ & $\mathrm{R}^{2}$ & $\begin{array}{c}\text { Adj. } \\
\mathrm{R}^{2}\end{array}$ & $\begin{array}{c}\text { Pred. } \\
\mathrm{R}^{2}\end{array}$ & Press \\
\hline Mean & $1.666 \mathrm{E}+005$ & 1 & $1.666 \mathrm{E}+005$ & & & & & & & \\
\hline Linear & 181.24 & 4 & 45.31 & 0.38 & 0.8209 & 10.93 & 0.0674 & -0.1103 & -0.3360 & 3594.85 \\
\hline $2 \mathrm{FI}$ & 35.85 & 6 & 5.98 & 0.036 & 0.9997 & 12.84 & 0.0807 & -0.5322 & -2.7127 & 9989.75 \\
\hline Quadratic & 2444.04 & 4 & 611.01 & 227.11 & $<0.0001$ & 1.64 & 0.9890 & 0.9750 & 0.8528 & 396.15 \\
\hline Cubic & 25.98 & 9 & 2.89 & 1.60 & 0.4431 & 1.34 & 0.9987 & 0.9832 & & + \\
\hline Residual & 3.61 & 2 & 1.81 & & & & & & & \\
\hline Total & $1.693 \mathrm{E}+005$ & 26 & 6512.11 & & & & & & & \\
\hline
\end{tabular}

The quality of the model evaluated based on the correlation coefficient value, $\mathrm{R}^{2}$, this $\mathrm{R}^{2}$ value for equation 2 is 0.989 (Table 8). This showed that $98.9 \%$ of the total variation in the biodiesel yield was attributed to the experimental variables studied. The $\mathrm{R}^{2}$ value close to unity, the better the model will be as it will give predicted values that are closer to the actual values for the response. From the ANOVA and regression analysis of Table 5 and Table 7 respectively it can be seen that the linear terms of $\mathrm{A}$, $\mathrm{B}$, and $\mathrm{C}$, the quadratic term $\mathrm{A}^{2}$ and $\mathrm{B}^{2}$ are significant (because Prob > F less than 0.05), but the interactions $\mathrm{BC}$ and $\mathrm{CD}$ are insignificant.

In Fig. 3 the predicted vs. actual values were obtained using the experimental data run correspondence, since the plot contains a line of slope unit (i.e. the line of perfect fit) with points corresponding to zero error between predicted values and actual. This shows the performance of the correlation in an evident way. Hence, the regression model equation granted a very accurate description of the experimental data, in which all the points are very close to the perfect fit. This outcome indicates that it was successful in creating the correlation between the four process parameters to FAME.

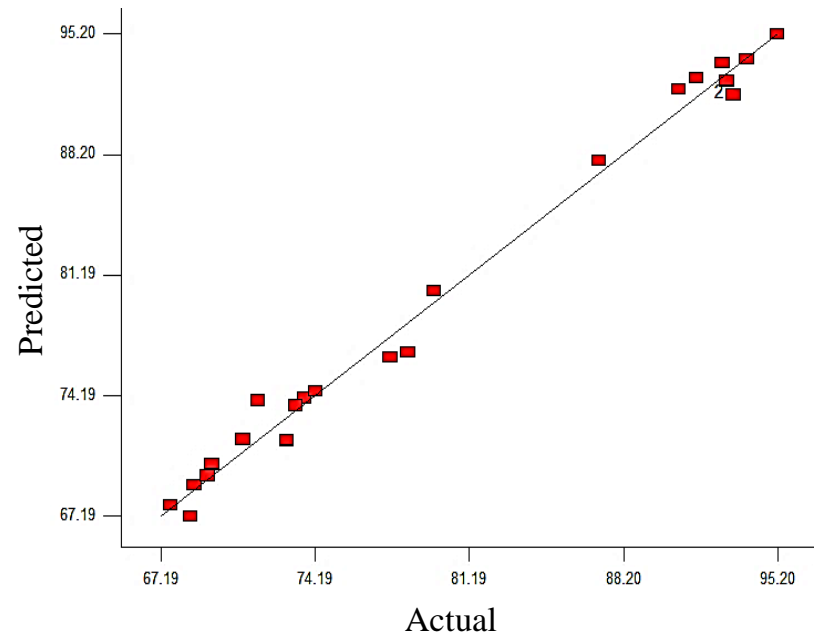

Fig. 3 Plot for the actual vs. predicted FAME yield. 


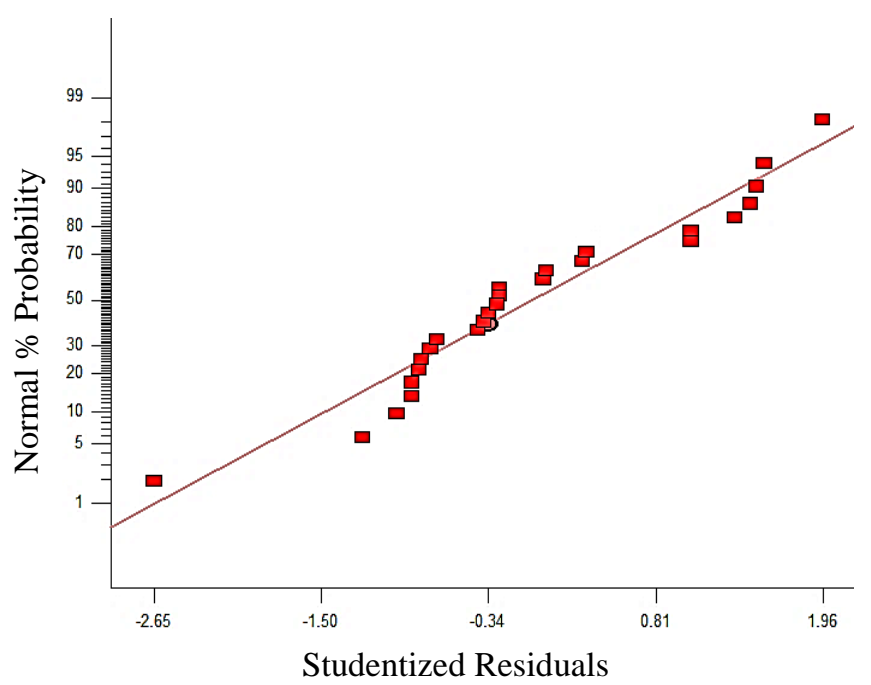

Fig. 4 Normal plots of residuals.

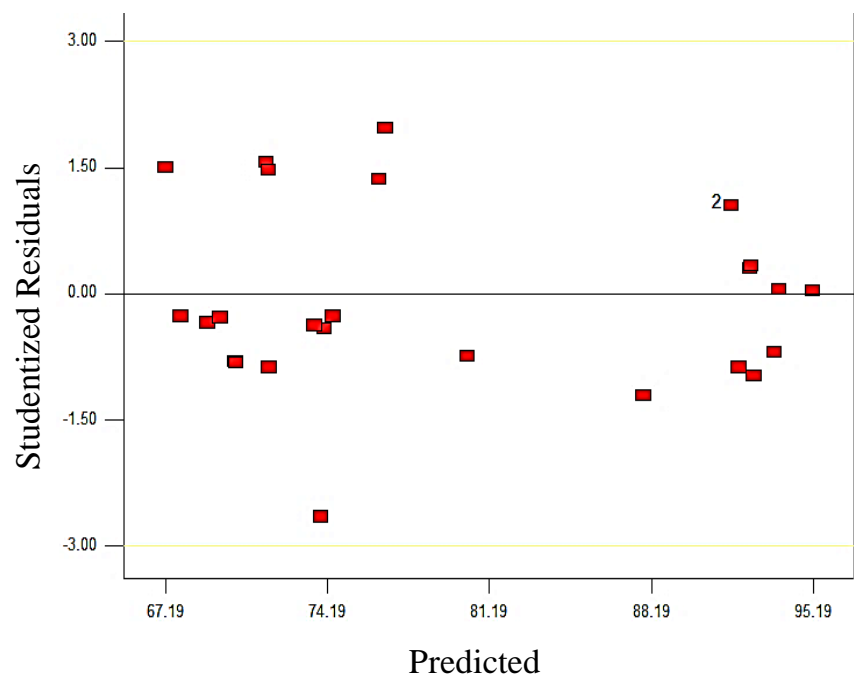

Fig. 5 Residual vs. predicted values.

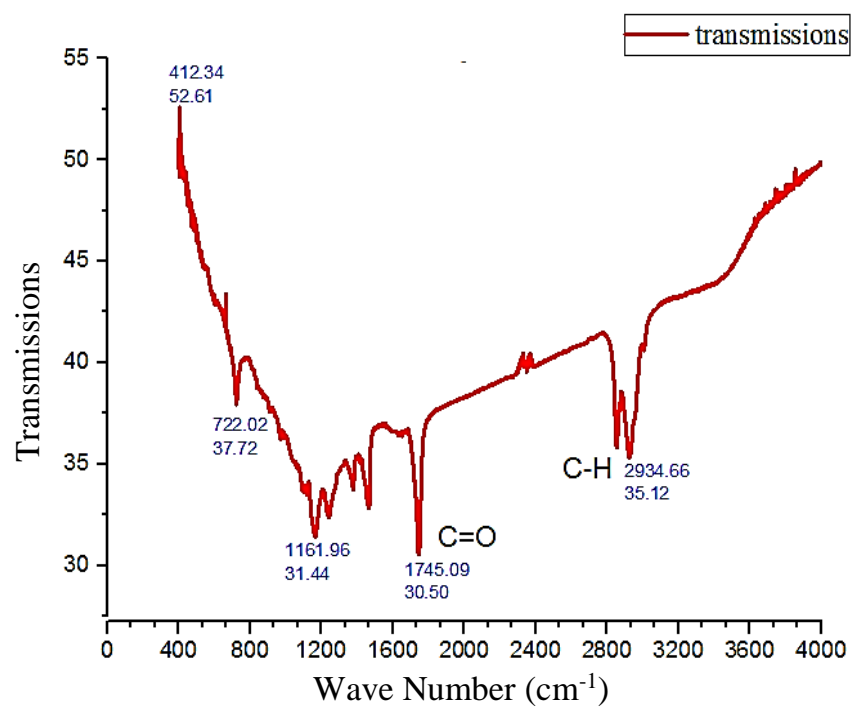

Fig. 6 The FT-IR produced biodiesel process.

In Fig. 4, as shown above, the standard probability plot shows the residuals following a normal distribution, in the case of this experiment the points in the plots shows fit to a straight line in the figure, this shows that the quadratic model satisfies the analysis of the assumptions of variance (ANOVA) i.e. the error distribution is approximately normal.

From the model, the residuals should be structure less; in particular, they should be unrelated to any other variable including the predicted response. The plot of these response value tests the assumption of constant variance and this shows random distribution which justifying no need for any alteration to minimize personal error (Fig. 5).

\subsection{Analysis of Fourier transforms infrared (FT-IR)}

Fourier transforms infrared spectroscopy; FT-IR was to analyze the function group presence in the produced biodiesel and its raw materials avocado peel oil. FT-IR analysis was performed using an instrument as shown in Fig. 6. One of the detections of transesterification efficiency of oil by determination of the active groups produced from these processes. The FT-IR spectra will be recorded at a surrounding temperature in the wavenumber between $4000-400 \mathrm{~cm}^{-1}$.

The biodiesel produced from the extracted avocado peel oil was analyzed by FT- IR spectrum. The main change that takes place during the conversion from triglyceride oil to biodiesel was the gain of $\mathrm{a} \mathrm{CH}_{3}$ carbon in the biodiesel product found in the range of 1438- $1459 \mathrm{~cm}^{-1}$ which is not present in the spectra of the oil. Biodiesel results in the formation of carbon-hydrogen bonds at $2855-3008 \mathrm{~cm}^{-1}$, ester functionality at $1738-1759 \mathrm{~cm}^{-1}$, the carbons at $1438-1459 \mathrm{~cm}^{-1}$, and carbon-oxygen bonds at 1171-1197 $\mathrm{cm}^{-1}$. C = O carbonyl compound (aldehydes, acids, etc) are the strong $\mathrm{C}=\mathrm{O}$ stretching absorption bands in the region of $1870-1540 \mathrm{~cm}^{-1}$. If ester this band appears in the $1705 \mathrm{~cm}^{-1}$ and $1658 \mathrm{~cm}^{-1}$. C-O-C (Ethers), these stretching vibrations produce a strong brand in the $1200-900 \mathrm{~cm}^{-1}$ region. Other identifying peaks found in the oil were at $2926 \mathrm{~cm}^{-1}$ and 2855 $\mathrm{cm}^{-1}$ that represent $\mathrm{sp}^{3}$ hybridized carbon molecules that are found in the long carbon chain of the biodiesel [8].

\section{Conclusion}

In this study, biodiesel was produced by the transesterification method using the oil extracted from the avocado peel, methanol as alcohol, and sodium hydroxide as a catalyst to produced biodiesel. The process parameters that affect the yield of FAME conversion have been studied by design expert 6.8 Software and the statistical analysis. The outputs of the experimental run conducted have been analyzed by using physicochemical parameter determination. The whole results show that the avocado peel oil could be used to produce biodiesel as a feedstock. The characterized physicochemical properties of the produced biodiesel from APO could be used as an alternative energy resource in engines.

The obtained biodiesel produce by the transesterification process was, ranged from 67.8 to $95.2 \%$. A 95.2\% FAME conversion was obtained using a methanol/oil ratio of $6: 1,1.21 \mathrm{~g}$ $\mathrm{NaOH}$, reaction time $67.5 \mathrm{~min}$, and $60{ }^{\circ} \mathrm{C}$ reaction temperature. The physicochemical properties (characterization) of produced biodiesel are, $(\mathrm{pH}$ of 7.8 , the specific gravity of 0.88 , density at $15{ }^{0} \mathrm{C}, \mathrm{kg} / \mathrm{m}^{3}$, the kinematic viscosity of biodiesel was found to be $4.22 \mathrm{~m}^{2} \cdot \mathrm{s}^{-1}$ at $40{ }^{0} \mathrm{C}$, the flashpoint was $161{ }^{\circ} \mathrm{C}$ and Cetane number of 49 are well-matched the international standards and compared to ASTM and EN standards, which indicates it is possible to produce quality biodiesel.

Finally, this result shows that the oil extracted from avocado peel can be used for biodiesel production as an alternative feedstock. 


\section{References}

[1] Huang, D., Zhou, H. and Lin, L., 2012. Biodiesel: an alternative to conventional fuel. Energy Procedia, 16, pp.1874-1885.

[2] Gashaw, A., Getachew, T. and Teshita, A., 2015. A review on biodiesel production as alternative fuel. J. For. Prod. Ind, 4(2), pp.80-85.

[3] Pinto, A.C., Guarieiro, L.L., Rezende, M.J., Ribeiro, N.M., Torres, E.A., Lopes, W.A., Pereira, P.A.D.P. and Andrade, J.B.D., 2005. Biodiesel: an overview. Journal of the Brazilian Chemical Society, 16(6B), pp.1313-1330.

[4] Elkady, M.F., Zaatout, A. and Balbaa, O., 2015. Production of biodiesel from waste vegetable oil via KM micromixer. Journal of Chemistry, 2015.

[5] Dash, S.K. and Lingfa, P., 2018, June. An overview of biodiesel production and its utilization in diesel engines. In IOP Conference Series: Materials Science and Engineering (Vol. 377, No. 1, p. 012006). IOP Publishing.

[6] Van Gerpen, J., 2005. Biodiesel processing and production. Fuel processing technology, 86(10), pp.10971107.

[7] Demirbaş, A. and Kara, H., 2006. New options for conversion of vegetable oils to alternative fuels. Energy Sources, Part A, 28(7), pp.619-626.

[8] Hiwot, T., 2017. Determination of oil and biodiesel content, physicochemical properties of the oil extracted from avocado seed (Persea Americana) grown in Wonago and Dilla (gedeo zone), southern Ethiopia. Chem. Int, 3(3), pp.311-319.

[9] Ayoola, A.A., Hymore, F.K., Obande, M.A. and Udeh, I.N., 2012. Optimization of experimental conditions for biodiesel production. International Journal of Engineering \& Technology, 12(6), pp.130-133.

[10] Ogunwole, O.A. and Adedipe, O., 2012. Production of biodiesel from jatropha oil (curcas oil). Research Journal of Chemical Sciences, 2(11), pp. 30-33.

[11] Gude, V.G., Patil, P.D., Grant, G.E. and Deng, S., 2012. Sustainable Biodiesel Production, Second world Sustainable forum, 1-14.

[12] Jalata, Z., 2021. Current Status, Potentials and Opportunities of Avocado Production as an Alternative Crop: the Case of Ethiopia: A Review. Agricultural Reviews.

[13] Mora-Sandí, A., Ramírez-González, A., CastilloHenríquez, L., Lopretti-Correa, M. and Vega-Baudrit, J.R., 2021. Agro-Industrial Avocado (Persea americana) Waste Biorefinery.

[14] Aydin, K., Sarıbıyık, O.Y., Özcanlı, M., Serin, H. and Serin, S., 2010. Biodiesel Production from Ricinus Communis Oil and Its Blends with Soybean Biodiesel. Strojniski Vestnik/Journal of Mechanical Engineering, 56(12).

[15] Demirbas, A., 2008. Comparison of transesterification methods for production of biodiesel from vegetable oils and fats. Energy Conversion and Management, 49(1), pp.125-130.

[16] Prah, E., 2010. Biodiesel analytical development and characterisation (Doctoral dissertation, Stellenbosch: University of Stellenbosch).

[17] Indhumathi, P., Syed Shabudeen, P.S., Shoba, U.S, 2014. A Method for Production and Characterization of Biodiesel from. International Journal of Bio-Science and Bio-Technology, 6(5), pp.111-122. 